\title{
Chemical signatures of surface microheterogeneity on liquid mixtures
}

Shinichi Enami, Shinnosuke Ishizuka, and Agustín J. Colussi

Citation: J. Chem. Phys. 150, 024702 (2019); doi: 10.1063/1.5055684

View online: https://doi.org/10.1063/1.5055684

View Table of Contents: http://aip.scitation.org/toc/jcp/150/2

Published by the American Institute of Physics 


\title{
Chemical signatures of surface microheterogeneity on liquid mixtures
}

\author{
Cite as: J. Chem. Phys. 150, 024702 (2019); doi: 10.1063/1.5055684 \\ Submitted: 9 September 2018 - Accepted: 10 December 2018 • \\ Published Online: 8 January 2019
}

Shinichi Enami, ,a) (D) Shinnosuke Ishizuka, (D) and Agustín J. Colussi ${ }^{2, a)}$ (D)

\begin{abstract}
AFFILIATIONS
${ }^{1}$ National Institute for Environmental Studies, 16-2 Onogawa, Tsukuba 305-8506, Japan

${ }^{2}$ Linde Center for Global Environmental Science, California Institute of Technology, Pasadena, California 91125, USA
\end{abstract}

\author{
a) Authors to whom correspondence should be addressed: enami.shinichi@nies.go.jp, Tel.: 81-29-850-2770 \\ and ajcoluss@caltech.edu, Tel.: 1-626-395-6350.
}

\begin{abstract}
Many chemical reactions in Nature, the laboratory, and chemical industry occur in solvent mixtures that bring together species of dissimilar solubilities. Solvent mixtures are visually homogeneous, but are not randomly mixed at the molecular scale. In the allimportant binary water-hydrotrope mixtures, small-angle neutron and dynamic light scattering experiments reveal the existence of short-lived $(<50 \mathrm{ps})$, short-ranged $(\sim \mathrm{nm})$ concentration fluctuations. The presence of hydrophobic solutes stabilizes and extends such fluctuations into persistent, mesoscopic $(10-100 \mathrm{~nm})$ inhomogeneities. While the existence of inhomogeneities is well established, their impacts on reactivity are not fully understood. Here, we search for chemical signatures of inhomogeneities on the surfaces of $\mathrm{W}: \mathrm{X}$ mixtures $(\mathrm{W}=$ water; $\mathrm{X}$ = acetonitrile, tetrahydrofuran, or 1,4-dioxane) by studying the reactions of Criegee intermediates (CIs) generated in situ from $\mathrm{O}_{3}(\mathrm{~g})$ addition to a hydrophobic olefin (OL) solute. Once formed, CIs isomerize to functionalized carboxylic acids (FC) or add water to produce $\alpha$-hydroxy-hydroperoxides (HH), as detected by surface-specific, online pneumatic ionization mass spectrometry. Since only the formation of $\mathrm{HH}$ requires the presence of water, the dependence of the $\mathrm{R}=\mathrm{HH} / \mathrm{FC}$ ratio on water molar fraction $x_{w}$ expresses the accessibility of water to CIs on the surfaces of mixtures. The finding that $\mathrm{R}$ increases quasi-exponentially with $x_{w}$ in all solvent mixtures is consistent with CIs being preferentially produced (from their OL hydrophobic precursor) in X-rich, long-lived OL: $\mathrm{X}_{m} \mathrm{~W}_{n}$ interfacial clusters, rather than randomly dispersed on W:X surfaces. $\mathrm{R}$ vs $x_{w}$ dependences therefore reflect the average $\langle m, n\rangle$ composition of OL: $\mathrm{X}_{m} \mathrm{~W}_{n}$ interfacial clusters, as weighted by cluster reorganization dynamics. Water in large, rigid clusters could be less accessible to CIs than in smaller but more flexible clusters of lower water content. Since mesoscale inhomogeneities are intrinsic to most solvent mixtures, these phenomena should be quite general.
\end{abstract}

Published under license by AIP Publishing. https://doi.org/1 0.1063/1.5055684

\section{INTRODUCTION}

Both in the laboratory and in large-scale operations, most chemical reactions are performed in solvent mixtures tailored to bring together reactants of dissimilar solubilities. ${ }^{7}$ Important natural processes also take place in aqueous organic media of complex compositions..$^{2-4}$ Solvents not only allow reactant molecules to get in close contact but also influence reactions in various ways and at different scales. ${ }^{5}$ At one time, solvent effects in chemical reactions were rationalized in terms of transition state theory and continuous models based on macroscopic descriptors, such as solvent viscosity and dielectric constants. ${ }^{7}$ This perspective, however, has had mixed success over the years. A deeper understanding of the solvent effects emerged from the results of small and wideangle X-ray ${ }^{6}$ and small angle neutron scattering experiments, which revealed concentration fluctuations in the bulk and the surface of macroscopically homogeneous, visually clear, "internally mixed" binary solvent mixtures. ${ }^{7-10}$ These concentration (or structural) fluctuations are brief (tens of picoseconds) inhomogeneities in the $\sim 1 \mathrm{~nm}$ scale that happen to peak in the concentration ranges that give rise to thermodynamic and transport properties anomalies in binary mixtures. ${ }^{1-17}$

The addition of solutes to binary mixtures generates the larger (in the 10-100 $\mathrm{nm}$ mesoscale), more persistent (from 
milliseconds to years) non-covalent aggregates detected by dynamic light scattering experiments in many systems. ${ }^{18-22}$ These aggregates also appear in the mass spectra of liquid jets produced by adiabatic expansion of solutions of hydrophobic species in aqueous organic mixtures. ${ }^{23-26}$ The universality of this phenomenon opens up the possibility that molecular environments could be engineered in solvent mixtures for steering the course of chemical reactions in unanticipated ways. ${ }^{12,27-29}$ It also leads to the realization that spontaneous compartmentalization at the mesoscale in complex liquid mixtures, by potentially supporting disjoint but coupled chemical processes in apparently homogeneous systems, is an alternative mechanism to the reaction-diffusion Turing model of the onset of complexity and pattern formation in Nature. ${ }^{30-32}$

Water is a major component of natural systems; however, it is rarely present as a neat water, but as a solvent or distributed in diverse materials. Arguably, aqueous interfaces are where most interesting things happen: solutes of dissimilar characteristics meet at aqueous interfaces with hydrophobic media, and chemical reactions proceed much faster and sometimes along different pathways from bulk media. ${ }^{33-37}$ Most biochemical reactions in vivo take place within self-organized enzymatic cavities and related micellar arrays, where waterinsoluble species react with aqueous solutes at the intervening interfaces.

Aqueous organic interfaces are widespread in the environment, ${ }^{38,39}$ most conspicuously as the organic films that cover the oceans, and on atmospheric aqueous organic aerosols. ${ }^{40,41}$ These systems, which generally consist of water plus amphiphilic and hydrophobic organic species, can be internally mixed, phase-separated into aqueous cores covered by organic shells, or phase-separated into segregated aqueous and organic domains, depending on the inorganic solutes, temperature, relative humidity, and the abundance and functionality of organic species. ${ }^{2,42-50}$ It is apparent that the rates and products of the chemical processes associated with the formation, growth and aging of organic aerosols, and the exchange of gases between the atmosphere and the oceans may critically depend on whether organics are present as solutes in internally mixed or in phase-separated mixtures. In this context, phase separation refers to the meso/macroscale. The length scale at which chemical reactions occur, however, is much smaller. The bulk and the surfaces of segregated solvent mixtures, and even those of "internally mixed" mixtures can be inhomogeneous at the molecular level. Self-clustering of hydrotrope molecules into discrete islands or domains on the surface of aqueous solutions, ${ }^{51-53}$ in conjunction with vertical concentration and solvation gradients through air-liquid interfacial layers, could significantly affect chemistry in such media. ${ }^{54-59}$

In the past, liquid interfaces remained invisible to conventional photon or particle scattering techniques. The advent of molecular dynamics studies, surface sensitive techniques, such as small-angle X-ray and neutron scattering, neutron and X-ray reflectometry, second harmonic generation

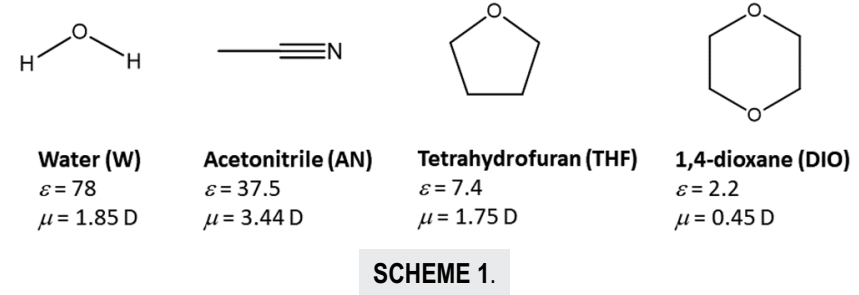

spectroscopy, and photoelectron microscopy has produced a wealth of structural information. ${ }^{52,60,61}$ A valid question is whether the features revealed by these studies on the surfaces of binary solvent mixtures could assist us in understanding and predicting the products and rates of reactions, which necessarily involve additional components. One caveat is that liquid structures are essentially dynamic, and therefore, the length and time scales of the entities detected by physical techniques may not be directly relevant to chemical reactions. The concentration fluctuations detected by the scattering techniques in binary mixtures are not the persistent mesoscale aggregates generated upon the addition of reactant solutes. These are important issues in several fields, which we address herein in experiments where the surfaces of liquid mixtures are probed for molecular aggregates by reacting molecules. ${ }^{62}$

The reacting molecules in our experiments are carbonyl oxide Criegee intermediates (CIs) on the gas-liquid interfaces of $\mathrm{W}: \mathrm{X}$ mixtures $(\mathrm{W}=$ water; $\mathrm{X}=$ acetonitrile, $\mathrm{AN}$; tetrahydrofuran, THF; and 1,4-dioxane, DIO) (Scheme 1). CIs are generated in situ by reacting $\mathrm{O}_{3}(\mathrm{~g})$ with $\beta$-caryophyllene $\left(\mathrm{a} \mathrm{C}_{15}{ }^{-}\right.$ diolefin, denoted as $\beta$-C or OL from now on) on the surface of its solutions in W:X mixtures. These solvents are fully miscible, but are known to display bulk microheterogeneity. ${ }^{28} \mathrm{~A}$ previous sum-frequency spectroscopy study showed that the surface of W:AN mixtures undergoes a sharp transition into a structurally uniform interfacial layer below water molar fraction $x_{w} \approx 0.93 . .^{51,53,63}$ Related molecular dynamics calculations refined such scenario and revealed that the outermost interfacial layers are actually microheterogeneous, being populated by disjointed W:AN clusters in proportions that depend on $x_{w}$ in a non-trivial way. ${ }^{64,65}$ In our experiments, the products of CIs reactions are monitored in real time via surface-specific online pneumatic ionization mass spectrometry (o-PI-MS) (see below). More specifically, we track the relative yields of the products of competing reactions of the CIs as functions of $x_{w}$. We report that relative yields are strong exponential functions of $x_{w}$ in all mixtures and analyze the implications of these results.

\section{EXPERIMENTAL SECTION}

In our experiments, $(\beta-\mathrm{C}+\mathrm{NaCl})$ solutions in $\mathrm{W}: \mathrm{X}$ mix-

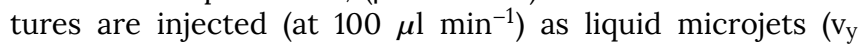
$=21 \mathrm{~cm} / \mathrm{s}$, see Fig. S1) into the spraying chamber of the mass spectrometer (ES-MS, Agilent 6130 Quadrupole LC/MS Electrospray System at NIES, Japan) through an electrically grounded stainless-steel syringe needle $(100 \mu \mathrm{m}$ bore). The 
spraying chamber is flushed with $\mathrm{N}_{2}$ (g) and maintained at $1 \mathrm{~atm}$, at $298 \mathrm{~K}$. The liquid microjets are fragmented (within $\tau_{\mathrm{R}}$ $<10 \mu \mathrm{s})^{66,67}$ into charged microdroplets ${ }^{68,69}$ by a high velocity $(160 \mathrm{~m} / \mathrm{s})$ nebulizer gas $\left[\mathrm{N}_{2}(\mathrm{~g})\right]$ flowing through a sheath coaxial with the syringe needle. ${ }^{70}$ In these events, the kinetic energy of the nebulizing gas provides energy for creating the surfaces of the microdroplets and for charging the microdroplets by separating the anions and cations already present in the microjets. Nebulization is the single event that generates the net charges that ultimately appear as mass spectral signals. That the droplets of mists produced by nebulizing liquids are charged was known for more than a century. 69,71 This charging process does not require, ${ }^{72,73}$ although may be enhanced by, the presence of an electric field. In the supplementary material (see Validation Experiments), we show that in our setup the creation of net charge is mainly due to pneumatic nebulization rather than to the applied electric field needed to deflect charged microdroplets towards the mass analyzer (see Fig. S1). For this reason, we label our technique online pneumatic ionization mass spectrometry o-PI-MS, rather than electrospray ionization mass spectrometry. In this regard, it is important to realize that "electrospray ionization mass spectrometers" are not all alike. The main differences are whether the needle injector is grounded and whether the microjets are directly projected towards mass analyzer or not. ${ }^{74}$ Our approach to studying interfacial processes via o-PI-MS is not a new idea. In their seminal 1984 paper, Yamashita and Fenn had already suggested that electrospray ionization mass spectrometry could be used to investigate liquid interfaces. ${ }^{75}$

CIs are produced upon exposing to $\mathrm{O}_{3}(\mathrm{~g})$ on the surfaces of liquid microjets containing $\beta-\mathrm{C}$. We chose $\beta-\mathrm{C}$ as the CIs precursor for its exceptional reactivity towards $\mathrm{O}_{3}(\mathrm{~g})$, which leads to significant conversions during the short $\tau_{R}$ $<10 \mu$ s lifetimes of the intact microjets. ${ }^{54,76-78}$ Reaction products are detected without any manipulation by o-PIMS in less than a $1 \mathrm{~ms}$. $\mathrm{NaCl}$ is added to bind the neutral $\alpha$-hydroxy-hydroperoxide $(\mathrm{HH})$ products into detectable $\mathrm{Cl}^{-}$-adducts, which are unambiguously identified by the characteristic $\mathrm{M} / \mathrm{M}+2=3 / 1$ ratio imparted by natural abundance of ${ }^{35} \mathrm{Cl} /{ }^{37} \mathrm{Cl}$. We verified that $\mathrm{Cl}^{-}$is inert towards $\mathrm{O}_{3}(\mathrm{~g})$ under present conditions. ${ }^{59}$ Additional experiments (see Validation Experiments in the supplementary material) show that the detected ions originate from species produced in the outermost interfacial layers of intact liquid microjets, rather than on the microdroplets produced by nebulization, or in gasphase reactions between $\mathrm{O}_{3}(\mathrm{~g})$ and evaporated $\beta-\mathrm{C}(\mathrm{g})$. See the supplementary material and Figs. S2-S4 for additional validation experiments. Further experimental details may be found in previous publications. ${ }^{37,59,70,77,79,80}$

Ozone was generated by flowing ultrapure $\mathrm{O}_{2}(\mathrm{~g})$ (>99.999\%) through a silent discharge ozonizer (KSQ-050, Kotohira, Japan) and quantified via online ultraviolet-visible (UV-Vis) absorption spectrophotometry (Agilent 8453) before entering the spraying chamber. Reported $\left[\mathrm{O}_{3}(\mathrm{~g})\right]$ values correspond to concentrations on the surface of the liquid microjets, which we estimate by multiplying the concentrations determined by absorption spectrophotometry by a $\sim 1 / 12$ factor due to dilution by the nebulizing gas flow. Conditions used these experiments were as follows: drying nitrogen gas flow rate: $121 \mathrm{~min}^{-1}$; drying nitrogen gas temperature: 340 ${ }^{\circ} \mathrm{C}$; capillary inlet voltage: $+3.5 \mathrm{kV}$ relative to the grounded injector; and fragmentor voltage value: $60 \mathrm{~V}$. Fresh solutions were prepared daily using ultrapure water (resistivity $\geq 18.2$ $\mathrm{M} \Omega \mathrm{cm}$ at $298 \mathrm{~K}$ ) from a Millipore Milli-Q water purification system. The following chemicals were used as received: $\beta$ caryophyllene ( $\geq 98.5 \%$, Sigma-Aldrich), acetonitrile $(\geq 99.8 \%$, Wako), tetrahydrofuran ( $\geq 99.8 \%$, stabilizer free, Wako), 1,4dioxane ( $\geq 99.8 \%$, stabilizer free, Wako), $\mathrm{NaCl}(\geq 99.999 \%$, Sigma-Aldrich), L-ascorbic acid ( $\geq 99 \%$, Sigma-Aldrich), and octanoic acid ( $\geq 97 \%$, Wako).

\section{RESULTS AND DISCUSSION}

Figure 1 shows negative ion mass spectra of the products generated on the surface of $(1 \mathrm{mM} \beta-\mathrm{C}+0.2 \mathrm{mM} \mathrm{NaCl})$ in $x_{w}$ $=0.03,0.42$, and $0.74 \mathrm{~W}$ :AN liquid microjets exposed to $\mathrm{O}_{3}(\mathrm{~g})$ for $\tau_{R}<10 \mu \mathrm{s}$. The intense peaks at $\mathrm{m} / \mathrm{z} 305$ (307) correspond to $^{35,37} \mathrm{Cl}^{-}$-adducts of $\alpha$-hydroxy-hydroperoxides $(\mathrm{HH}){ }^{59,81-83}$ $\mathrm{HH}$ are formed in the reaction of $\mathrm{H}_{2} \mathrm{O}(\mathrm{MW}=18)$ with the Criegee intermediates (CIs) produced (via a primary ozonide POZ) from the addition of $\mathrm{O}_{3}(\mathrm{MW}=48)$ to the endo $\mathrm{C}=\mathrm{C}$ bond of $\beta-\mathrm{C}(\mathrm{MW}=204) \cdot{ }^{54,84}$ Neutral $\mathrm{HH}$ subsequently bind $\mathrm{Cl}^{-}$upon desolvation. ${ }^{85,86}$ Combined, these processes lead to $305(307)=204+48+18+35$ (37) (Scheme 2)..$^{59,82,83}$ The attachment of hydrated ${ }^{35,37} \mathrm{Cl}^{-}$to $\mathrm{HH}$ into stable, detectable gas-phase $\mathrm{HH}-\mathrm{Cl}^{-}$adducts takes place upon desolvation in the heated capillary section (not shown in Fig. S1) of the mass analyzer. The $\mathrm{m} / \mathrm{z} 251$ peak corresponds to anions of functionalized-carboxylates (FC) from the isomerization of CIs to carboxylic acids, followed by deprotonation: $251=204+$ 48 - 1 (Scheme 2). ${ }^{54,87}$ We also detected the signals of secondary species resulting from the reactions of primary products with $\mathrm{O}_{3}$. For example, $\mathrm{m} / \mathrm{z} 267$ signals correspond to species resulting from O-addition to the primary FC: $267=251$ $+16 .{ }^{54}$ These $\mathrm{m} / \mathrm{z} 267$ signals appeared in all solvent mixtures (see Figs. S5 and S6).

The $\mathrm{m} / \mathrm{z} 321$ (323) signals correspond to the chlorideadducts of a secondary neutral product of stoichiometry, formally amounting to the addition of $4 \mathrm{O}$-atoms plus a $\mathrm{H}_{2} \mathrm{O}$ molecule: $321(323)=204+64+18+35(37) \cdot{ }^{59,81-83}$ How $^{-}$ ever, water does not participate in their formation because the intensities of 321 (323) signals decrease at larger $x_{w}$ values, and their positions did not shift in experiments carried out in $\mathrm{H}_{2}{ }^{18} \mathrm{O}$ (Figs. S7-S10). ${ }^{59}$

Figures $\mathrm{S} 7-\mathrm{S} 9$ are the plots of product yields: $\mathrm{Y}\left(\mathrm{P}_{\mathrm{i}}\right)$ $=\mathrm{I}_{\mathrm{Pi}} / \Sigma \mathrm{I}_{\mathrm{Pj}}\left(\mathrm{I}_{\mathrm{Pi}}\right.$ is the intensity of the mass signal of product $\mathrm{P}_{\mathrm{i}}$ ) as functions of $x_{w}$ [at constant $\mathrm{O}_{3}(\mathrm{~g})$ exposures] in W:AN, W:THF, and W:DIO mixtures. Figure S10 shows $I_{p i}$ vs. $x_{w}$ plots at various $\mathrm{O}_{3}(\mathrm{~g})$ exposures in $\mathrm{W}$ :AN mixtures. The main result is that only the intensities of the HH 305 (307) signals increased, while all others decreased with $x_{w}$. Together, these observations imply that $\mathrm{HH}$ is produced from CIs $+\mathrm{H}_{2} \mathrm{O}$ 


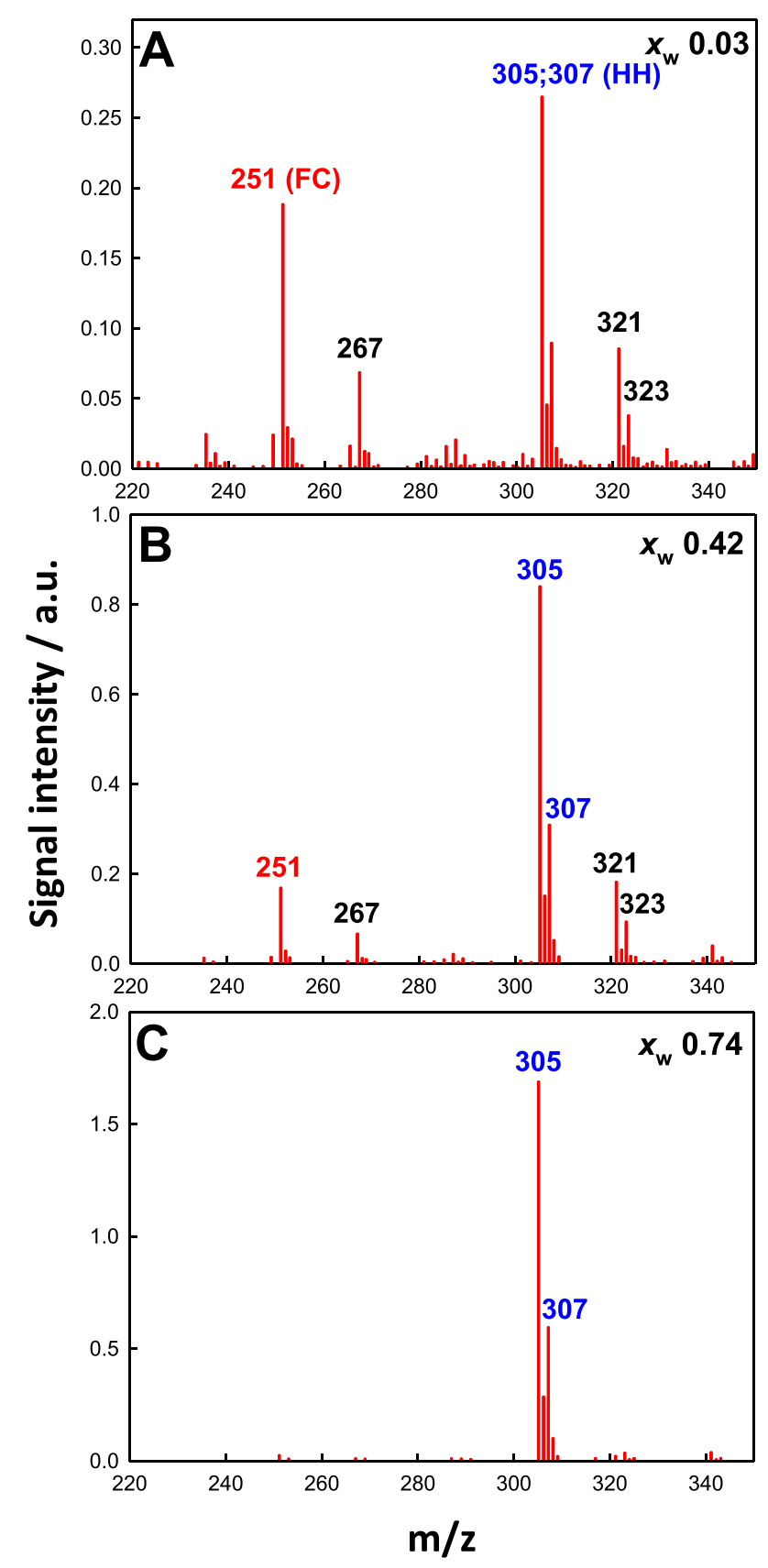

FIG. 1. Negative ion mass spectra of the products generated in the interfacial layers of ( $1 \mathrm{mM} \beta-C+0.2 \mathrm{mM} \mathrm{NaCl})$ in W:AN liquid microjets exposed to $E=5.3$ $\times 10^{11} \mathrm{O}_{3}(\mathrm{~g})$ molecules $\mathrm{cm}^{-3} \mathrm{~s}$. Water molar fractions in bulk W:AN mixtures: (a) $x_{w}=0.03$, (b) $x_{w}=0.42$, and (c) $x_{w}=0.74$.

in competition with other CIs reaction channels, as shown in Scheme 2.

Figures 2(a) and 2(b) show linear and semi-logarithmic plots of $\mathrm{R}=\mathrm{HH} / \mathrm{FC}=(305+307) / 251$ ratios of mass spectral signal intensities as functions of $x_{w}$ in W:AN, W:THF, and W:DIO mixtures at constant $\mathrm{O}_{3}(\mathrm{~g})$ exposure. The accessible $x_{w}$ ranges were determined either by $\beta-C$ solubility in each $\mathrm{W}: \mathrm{X}$ mixture or by low signal-to-noise ratios. The data points in Figs. 2(a) and 2(b) are the averages of three separate experiments. The error bars do not exceed the size of symbols in most cases.

Below, we analyze the physicochemical underpinnings of the steep, positive R vs $x_{w}$ dependences shown in Figs. 2(a) and 2(b). It should be borne in mind that our experiments probe the composition of the outermost interfacial layers rather than the bulk liquids. Therefore, $\mathrm{R}$ vs $x_{w}$ trends could depend on the relative affinities of the neutral $\mathrm{HH}$ and functionalized carboxylic acid products for the liquid surfaces. In this regard, note that the 252 undissociated carboxylic acids and the $270 \alpha$-hydroxy-hydroperoxides are both neutral, of similar molecular sizes and amphiphilic, because both possess polar O-containing functional groups on a hydrophobic $\mathrm{C}_{15}$ hydrocarbon framework. Therefore, their propensities for air-liquid interfaces are expected to be similar and weakly dependent on $x_{w}$ in aqueous organic mixtures. ${ }^{88,89}$ The degree of ionization of the 252 carboxylic acids into the detected $\mathrm{m} / \mathrm{z}=251 \mathrm{FC}$ anions, however, should increase with $x_{w}$, by analogy with the $x_{w}$-dependences of the octanoate $\mathrm{m} / \mathrm{z} 143$ mass signal intensities from octanoic acid solutions both in W:AN and W:THF mixtures (Figs. S11 and $\mathrm{S} 12)$. Ascorbate $\mathrm{m} / \mathrm{z} 175$ mass signal intensities in ascorbic acid dissolved in $\mathrm{W}$ :AN mixtures follow a similar trend (Fig. S13).

Therefore, if $\mathrm{R}=\mathrm{HH} / \mathrm{FC}$ ratios were determined by relative surface affinities and acid dissociation, they should have decreased with $x_{w}$ in all cases, in striking contrast with the results shown in Fig. 2. By assuming that the polarities of the CIs and the transition states for their isomerization into functionalized acids are similar, i.e., that CIs isomerization rates are weakly dependent on $x_{w}$, we infer that the strong positive $\mathrm{R}$ vs $x_{w}$ dependences arise from the acceleration of $\mathrm{CIs}+\mathrm{H}_{2} \mathrm{O}=\mathrm{HH}$ reactions in water-rich mixtures. The implication is that the availability of water to CIs in these solvent mixtures is a strong non-linear function of their water content. This finding challenges expectations because if $\beta$ $\mathrm{C}$ and the cosolvents were randomly mixed at the molecular scale, R vs $x_{w}$ plots should have been nearly linear functions of $x_{w}$.

Noticeably, the R vs $x_{w}$ plots of Fig. 2 are not smooth, i.e., show discernible structure, and depend on $\mathrm{X}$ in $\mathrm{W}: \mathrm{X}$ mixtures. Regarding the source of these differences, note that $\mathrm{AN}, \mathrm{THF}$, and DIO can accept $\mathrm{H}$-bonds from water (AN can also donate a H-bond) but their molecular dipole moments are quite different. AN is highly polar: $\mu=3.44 \mathrm{D}$, THF and $\mathrm{W}$ are less polar and have similar dipole moments: $\mu=1.75 \mathrm{D}$ and $1.85 \mathrm{D}$, respectively, whereas symmetrical DIO has a small dipole moment: $\boldsymbol{\mu}=0.45 \mathrm{D}$, due to non-planarity (Scheme 1). In Fig. 2(b), it is possible to distinguish that $\mathrm{R}$ in W:AN mixtures sharply increases 2.7 times in the narrow $0.13 \leq x_{w} \leq 0.19$ range, followed by a rather flat section (only a $\sim 30 \%$ increase) 


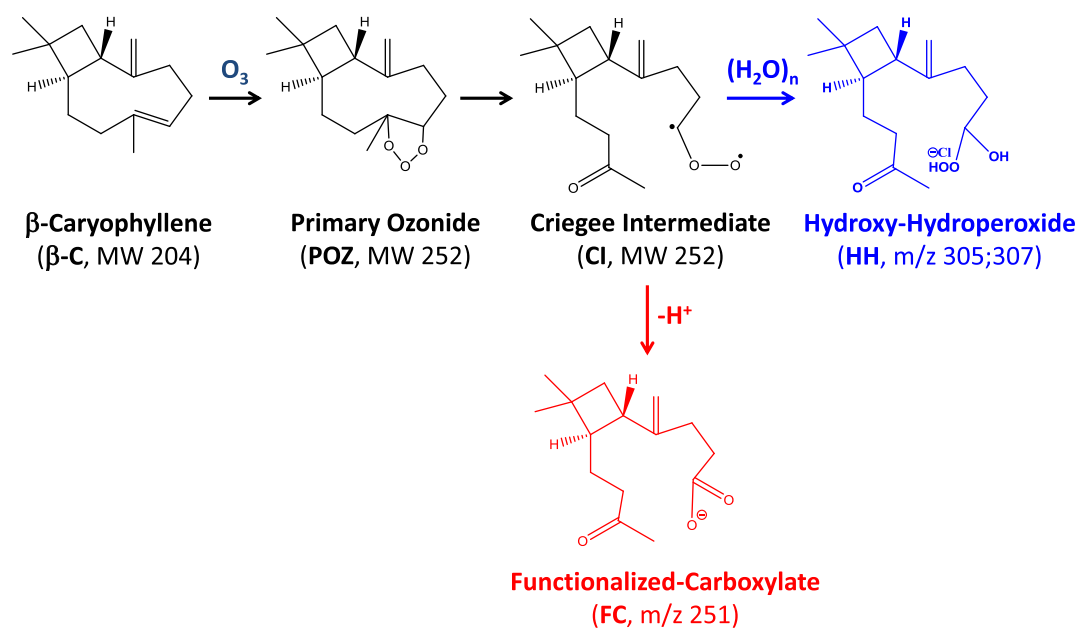

SCHEME 2. Formation of $\alpha$-hydroxyhydroperoxides $(\mathrm{HH}$, detected as chloride adducts at $\mathrm{m} / \mathrm{z} 305 ; 307)$ and functionalized-carboxylates ( $\mathrm{FC}, \mathrm{m} / \mathrm{z}$ 251) from the ozonolysis of $\beta-C$ at air-liquid interfaces. Structures shown are the representatives of possible isomers. in the $0.19 \leq x_{w} \leq 0.49$ interval, before increasing again $\sim 10$ times at $x_{w}=0.74$. These transitions bring to mind a recent photoelectron ejection spectroscopic study, which reported that the AN population of the outermost interfacial layers of W:AN mixtures decreased in three stages as a function of $x_{w} \cdot{ }^{65}$ The same study also reported the orientations of AN molecules at the interface, but gave no indication about the composition or the dimensions of the interfacial W:AN domains in each region. The molecular dynamics calculations later suggested that AN on the surface of W:AN mixtures is present as discrete clusters rather than as continuous films. ${ }^{64}$ Significantly, Fig. 2(b) shows that among these cosolvents, the R vs $x_{w}$ dependence in aqueous mixtures of the least polar DIO is the steepest and displays transitions as well. These findings are apparently in line with X-ray diffraction, mass spectrometry, and NMR relaxation studies of bulk W:DIO mixtures that reported three structural regions in the $0.1 \leq x_{w} \leq 0.7,0.8 \leq x_{w}$ $\leq 0.9$, and $0.93 \leq x_{w} \leq 1.0$ ranges. ${ }^{90}$ The transitions observed in Fig. 2 are physically significant, but do not detract from the fact that the large $R$ variations as a function of $x_{w}$ are well represented $\left(\rho^{2}=0.98\right)$ by exponentials: $R=a+b \exp \left(c x_{w}\right)$ or by strong power functions: $\mathrm{R}=\mathrm{a}+\mathrm{b} x_{w}{ }^{n}(n \geq 7)$ in all $\mathrm{W}: \mathrm{X}$ mixtures.

Based on our chemical experiments, we can only speculate about the origin of the significant differences between $\mathrm{R}$ vs $x_{w}$ dependences in W:AN, W:THF, and W:DIO mixtures. The overarching message is that microheterogeneity, both in the bulk and at interfaces, is an intrinsic feature of water:hydrotrope mixtures. ${ }^{16}$ The existence of sharp transitions between different sub-phases in our ternary OL:W:X mixtures indicates that the competition between the stability of the $\mathrm{H}$-bonding network of water, and the strength of $\mathrm{W}_{\mathrm{i}} \mathrm{X}_{\mathrm{j}}$ vs $X_{k}$ associations is a discontinuous function of cluster size and composition. The solvent effects on CIs reactions in our ternary mixtures are closely related to the $x_{w}$-dependences of the intensity, peak emission wavelength, and decay lifetime of 7-cyanoindole fluorescence in W:AN, W:THF, and W:DIO mixtures (see below). ${ }^{28}$ The correlations between the degree of dissociation of 2-naphthol and the rates of tert-butyl chloride hydrolysis with the composition of $\mathrm{W}_{\mathrm{i}} \mathrm{AN}_{\mathrm{j}}$ clusters as functions of $x_{w}$ in W:AN mixtures (Fig. S14) 23,25,26,91,92 support our interpretation that the R vs $x_{w}$ trends of Fig. 2 reflect the composition of $\beta-C: X_{m} W_{n}$ clusters. Note that not only AN, THF, and DIO but also dimethylsulfoxide, methanol, ethanol, isopropanol, and tert-butanol all show evidence of microheterogeneity. ${ }^{28}$ The implication is that microheterogeneity (both at shorter and longer time scales) may be a general phenomenon of water-hydrotrope mixtures and, therefore, that "molecularly homogeneous" aqueous mixtures may not exist. There is also thermodynamic evidence on microheterogeneity in aqueous mixtures. ${ }^{62,93}$

Our findings clearly show that the hydrophobic $\beta-\mathrm{C}$ solute is not randomly dispersed at the air-liquid interfaces of mixtures of water with amphiphilic organic solvents. ${ }^{12}$ The strongly non-linear R vs $x_{w}$ dependences in the three $\mathrm{W}$ :X solvent mixtures further reveal that the hydration of CIs takes place on intact liquid microjets of well-defined $x_{w}$ values (see Validation Experiments in the supplementary material). Since the hydrophobic $\mathrm{C}_{15}$-diolefin should be preferentially associated with the $\mathrm{X}$ hydrotropes rather than with water, CIs are expected to be generated in X-rich $\beta-C: \mathrm{X}_{m} \mathrm{~W}_{n}$ mixed clusters. ${ }^{94}$ The observed non-linear R vs $x_{w}$ dependences therefore reflect the accessibility of water to CIs embedded in $\mathrm{X}_{m} \mathrm{~W}_{n}$ clusters. $\mathrm{X}_{m} \mathrm{~W}_{n}$ clusters are entities that persist longer than milliseconds, as revealed by the time dependence of the second relaxation mode of the autocorrelation function of scattered light. ${ }^{18-20,95}$ The lifetimes of $\mathrm{X}_{m} \mathrm{~W}_{n}$ clusters are therefore much longer than the time window of our experiments: $\tau_{\mathrm{R}}<10 \mu \mathrm{s}$. The characteristic times of $\mathrm{X}$ and $\mathrm{W}$ exchange between $\mathrm{X}_{m} \mathrm{~W}_{n}$ clusters with the rest of the solution, however, are much shorter, as revealed by the fact that 7-cyanoindole fluorescence in W:AN, W:THF, and W:DIO mixtures decays as single exponentials in the $2-15$ ns range. ${ }^{28}$ Single exponential decays suggest that 7-cyanoindole fluoresces while embedded in $\mathrm{X}_{m} \mathrm{~W}_{n}$ clusters of average composition, rather than from an ensemble of $\mathrm{X}_{m} \mathrm{~W}_{n}$ clusters. Therefore, 

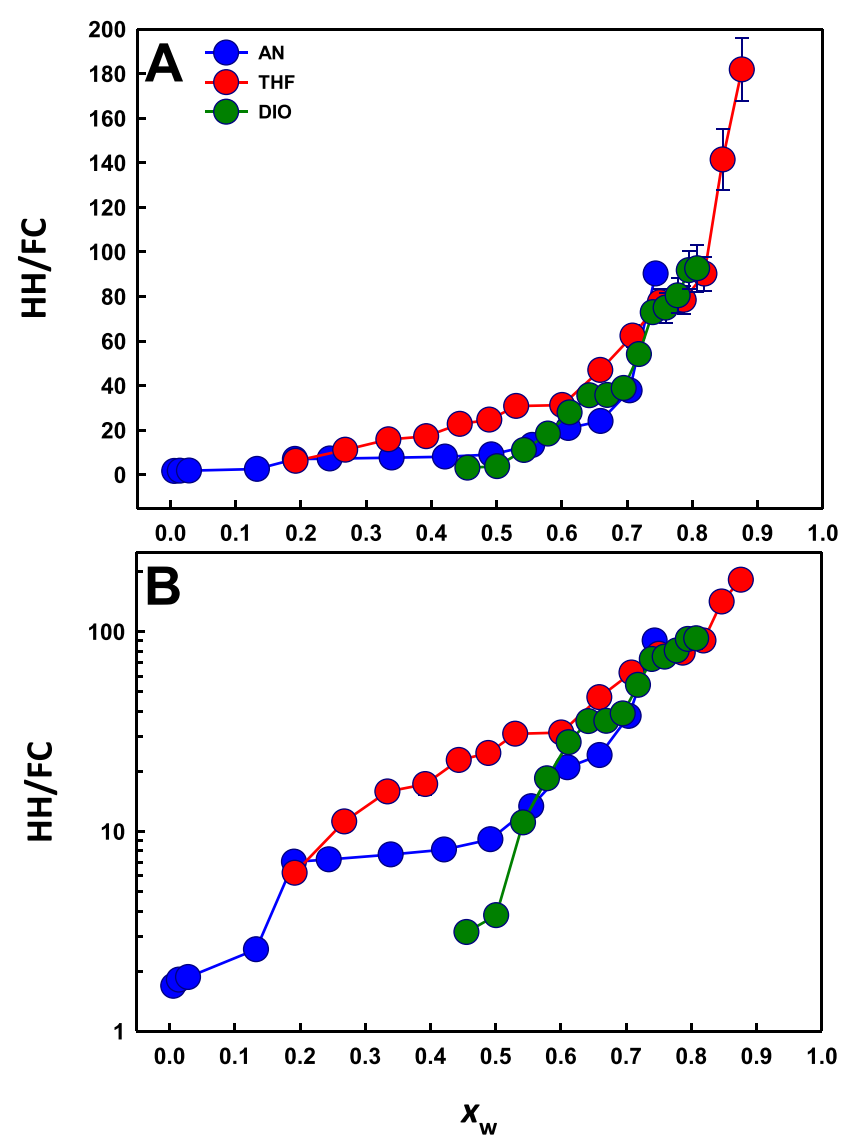

FIG. 2. Ratios $R=H H / F C=(305+307) / 251$ of mass spectral signal intensities as linear (a) and semi-logarithmic (b) functions of the molar fraction of bulk water, $x_{w}$, in experiments involving exposing microjets of $(1 \mathrm{mM} \beta$-caryophyllene +0.2 $\mathrm{mM} \mathrm{NaCl}$ ) solutions in W:AN, W:THF or W:DIO to $E=5.3 \times 10^{11} \mathrm{O}_{3}(\mathrm{~g})$ molecules $\mathrm{cm}^{-3} \mathrm{~s}^{-1}$. The error bars are within the symbols size in most cases. The lines are visual guides. Note that the HH/FC vs $x_{w}$ functions are not smooth and depend sensitively on the identity of the $\mathrm{X}$ cosolvent. However, the overall trends could be equally well-fitted $\left(\rho^{2}=0.98\right)$ by exponentials: $R=H H / F C=a+b \exp \left(c x_{w}\right)$ or power functions: $R=H H / F C=a+b x_{w}{ }^{n}(n \geq 7)$ in all W:X mixtures. The regression lines are not shown.

averaging takes place via $\mathrm{X}$ and $\mathrm{W}$ exchange in the sub-ns range scale. Since our thermalized $\mathrm{C}_{15}$ CIs should isomerize unimolecularly to $\mathrm{FC}$ in a longer time scale, we conclude that CIs reactions take place in persistent $\mathrm{X}_{m} \mathrm{~W}_{n}$ clusters of average composition. Therefore, the R vs $x_{w}$ plots of Fig. 2 should be related to the average composition of persistent $\beta-C: X_{m} W_{n}$ clusters as a function of $x_{w}$. This relationship, however, may not be direct. Since hydrophobic $\beta-\mathrm{C}$ is expected to be preferentially bound to $\mathrm{X}$ molecules, water accessibility could be limited by the reorganization dynamics of $\beta-\mathrm{C}: \mathrm{X}_{m} \mathrm{~W}_{n}$ clusters. Water in large, rigid clusters could take longer time to come in close contact with CIs than in smaller but more flexible clusters of lower water content. Thus, in principle, water accessibility to CIs should be determined by the convolution of average cluster composition and cluster reorganization rates.
In summary, our experiments reveal that chemical reactions on the surface of "internally mixed" aqueous organic solutions take place in clusters of compositions that are very different from the compositions of the bulk liquids.

This conclusion is particularly relevant to chemistry on the surface of aqueous organic aerosols. Atmospheric airliquid interfaces function as substrates for the adsorption of organic gases and vapors, and as reaction media for their subsequent chemical transformations. ${ }^{41,56,96-102}$ Our findings show that surface microheterogeneity plays an unanticipated role in atmospherically relevant reactions on the surface of "internally mixed" aqueous/organic aerosol particles. Chemical transformations of amphiphilic, hydrotropic, and hydrophobic species on the surface of aqueous organic aerosols should be expected as a rule to take place in microheterogeneous rather than homogeneous media. The implication is that reaction rates and products could be relatively independent of aerosol water content and/or relative humidity over wide ranges. ${ }^{101,103-108}$

\section{CONCLUSIONS}

The products of fast, competing reactions on the surface of water:hydrotrope mixtures were monitored as functions of mixture composition via online surface-sensitive mass spectrometry. It was found that the relative yields of the functionalized carboxylates $(\mathrm{FC})$ and $\alpha$-hydroxy-hydroperoxides $(\mathrm{HH})$ products of competing isomerization vs hydration reactions of Criegee intermediates depend quasi-exponentially rather than linearly on water molar fraction. Quasi-exponential dependences, however, are not smooth but display significant structure, which is consistent with the existence of distinct interfacial sub-phases suggested by other techniques. Our study demonstrates that the surfaces of "internally mixed" aqueous/organic solvent mixtures are not "well mixed," and are indirectly related to the composition of the bulk solvents. The notion that microheterogeneity is an intrinsic feature of interfaces separating aqueous organic mixtures from hydrophobic phases and could dramatically influence interfacial reactions should become a key concept in various fields.

\section{SUPPLEMENTARY MATERIAL}

See supplementary material for validation experiments and additional experimental data. This material is available free of charge via the Internet.

\section{ACKNOWLEDGMENTS}

We are grateful to Dr. Satoshi Inomata, Dr. Akihiro Fushimi, Dr. Kei Sato, and Dr. Yu Morino of NIES and Dr. Lijie $\mathrm{Li}$ and Dr. Michael Hoffmann of Caltech for valuable discussions. This work was supported in part by the JSPS KAKENHI (Grant Nos. 15H05328 and 15K12188). A.J.C. acknowledges support from the National Science Foundation, USA (Grant No. AGS-1744353). 


\section{REFERENCES}

${ }^{1}$ E. Buncel and R. A. Stairs, Solvent Effects in Chemistry (John Wiley \& Sons, 2015).

${ }^{2}$ A. Marsh, G. Rovelli, Y.-C. Song, K. L. Pereira, R. E. Willoughby, B. R. Bzdek, J. Hamilton, A. Orr-Ewing, D. O. Topping, and J. P. Reid, Faraday Discuss. 200, 639-661 (2017).

3J. P. Reid and R. M. Sayer, Chem. Soc. Rev. 32(2), 70-79 (2003).

${ }^{4}$ B. R. Bzdek and J. P. Reid, J. Chem. Phys. 147(22), 220901 (2017).

${ }^{5}$ L. O. Kononov, RSC Adv. 5(58), 46718-46734 (2015).

${ }^{6} \mathrm{~S}$. Prevost, T. Lopian, M. Pleines, O. Diat, and T. Zemb, J. Appl. Crystallogr, 49(6), 2063-2072 (2016).

${ }^{7}$ D. Subramanian, C. T. Boughter, J. B. Klauda, B. Hammouda, and M. A. Anisimov, Faraday Discuss. 167, 217-238 (2013).

${ }^{8}$ D. Subramanian, J. B. Klauda, P. J. Collings, and M. A. Anisimov, J. Phys. Chem. B 118(22), 5994-6006 (2014).

${ }^{9}$ T. Zemb and W. Kunz, Curr. Opin. Colloid Interface Sci. 22, 113-119 (2016).

${ }^{10}$ T. N. Zemb, M. Klossek, T. Lopian, J. Marcus, S. Schöettl, D. Horinek, S. F. Prevost, D. Touraud, O. Diat, and S. Marčelja, Proc. Natl. Acad. Sci. U. S. A. 113(16), 4260-4265 (2016).

${ }^{11}$ R. Halder and B. Jana, J. Phys. Chem. B 122, 6801-6809 (2018).

${ }^{12}$ T. Buchecker, S. Krickl, R. Winkler, I. Grillo, P. Bauduin, D. Touraud, A. Pfitzner, and W. Kunz, Phys. Chem. Chem. Phys. 19(3), 1806-1816 (2017).

${ }^{13}$ S. Enami and A. J. Colussi, J. Phys. Chem. B 118(7), 1861-1866 (2014).

${ }^{14}$ Y. Koga, Phys. Chem. Chem. Phys. 15(35), 14548-14565 (2013).

${ }^{15}$ A. Perera, B. Kežić, F. Sokolić, and L. Zoranić, in Molecular DynamicsStudies of Synthetic and Biological Macromolecules (InTech, 2012).

${ }^{16}$ A. Perera, R. Mazighi, and B. Kezic, J. Chem. Phys. 136(17), 174516 (2012).

${ }^{17}$ A. Ben-Naim, J. Phys. Chem. 93(9), 3809-3813 (1989).

${ }^{18}$ M. Sedlak, J. Phys. Chem. B 110(28), 13976-13984 (2006).

${ }^{19}$ M. Sedlak, J. Phys. Chem. B 110(9), 4329-4338 (2006).

${ }^{20}$ M. Sedlak, J. Phys. Chem. B 110(9), 4339-4345 (2006).

${ }^{21}$ M. Sedlak and D. Rak, J. Phys. Chem. B 118(10), 2726-2737 (2014).

${ }^{22}$ D. Subramanian and M. A. Anisimov, Fluid Phase Equilib. 362, 170-176 (2014).

${ }^{23}$ A. Wakisaka and T. Iwakami, J. Mol. Liq. 189, 44-51 (2014).

${ }^{24} \mathrm{~A}$. Wakisaka and T. Ohki, Faraday Discuss. 129, 231-245 (2005).

${ }^{25}$ A. Wakisaka, Y. Shimizu, N. Nishi, K. Tokumaru, and H. Sakuragi, J. Chem. Soc., Faraday Trans. 88(8), 1129-1135 (1992).

${ }^{26}$ A. Wakisaka, S. Takahashi, and N. Nishi, J. Chem. Soc., Faraday Trans. 91(22), 4063-4069 (1995).

${ }^{27}$ R. Dutta, A. Pyne, D. Mondal, and N. Sarkar, ACS Omega 3(1), 314-328 (2018).

${ }^{28}$ D. Mukherjee, L. I. O. Rodriguez, M. R. Hilaire, T. Troxler, and F. Gai, Phys. Chem. Chem. Phys. 20(4), 2527-2535 (2018)

${ }^{29} \mathrm{~K}$. Griebenow and A. M. Klibanov, J. Am. Chem. Soc. 118(47), 11695-11700 (1996).

${ }^{30}$ J. Boreyko, P. Caveney, S. L. Norred, C. Chin, S. T. Retterer, M. L. Simpson, and C. P. Collier, MRS Adv. 2(45), 2427-2433 (2017).

${ }^{31}$ K. Ruiz-Mirazo, C. Briones, and A. de la Escosura, Open Biol. 7(4), 170050 (2017).

${ }^{32}$ S. Kondo and T. Miura, Science 329(5999), 1616-1620 (2010).

${ }^{33}$ D. Aljawhary, R. Zhao, A. K. Y. Lee, C. Wang, and J. P. D. Abbatt, J. Phys. Chem. A 120, 1395-1407 (2016).

${ }^{34}$ J. K. Lee, D. Samanta, I. Nam, H. G. Nam, and R. N. Zare, Biophys. J. 114(3), 542a (2018).

${ }^{35}$ S. Mondal, S. Acharya, R. Biswas, B. Bagchi, and R. N. Zare, J. Chem. Phys. 148(24), 244704 (2018).

${ }^{36}$ I. Nam, H. G. Nam, and R. N. Zare, Proc. Natl. Acad. Sci. U. S. A. 115(1), 36-40 (2018).

${ }^{37}$ S. Enami, Y. Sakamoto, and A. J. Colussi, Proc. Natl. Acad. Sci. U. S. A. 111(2), 623-628 (2014)

${ }^{38}$ D. J. Donaldson and V. Vaida, Chem. Rev. 106(4), 1445-1461 (2006)
${ }^{39}$ Y. F. Cheng, H. Su, T. Koop, E. Mikhailov, and U. Poschl, Nat. Commun. 6 , 5923 (2015).

${ }^{40}$ D. J. Donaldson and D. Anderson, J. Phys. Chem. A 103(7), 871-876 (1999).

${ }^{41}$ D. J. Donaldson and K. T. Valsaraj, Environ. Sci. Technol. 44(3), 865-873 (2010).

${ }^{42}$ U. K. Krieger, C. Marcolli, and J. P. Reid, Chem. Soc. Rev. 41(19), 6631-6662 (2012).

${ }^{43}$ J. P. Reid, B. J. Dennis-Smither, N.-O. A. Kwamena, R. E. Miles, K. L. Hanford, and C. J. Homer, Phys. Chem. Chem. Phys. 13(34), 15559-15572 (2011). ${ }^{44}$ Y. Q. Qiu and V. Molinero, J. Am. Chem. Soc. 137(33), 10642-10651 (2015).

${ }^{45}$ H. O. T. Pye, B. N. Murphy, L. Xu, N. L. Ng, A. G. Carlton, H. Y. Guo, R. Weber, P. Vasilakos, K. W. Appel, S. H. Budisulistiorini, J. D. Surratt, A. Nenes, W. W. Hu, J. L. Jimenez, G. Isaacman-VanWertz, P. K. Misztal, and A. H. Goldstein, Atmos. Chem. Phys. 17(1), 343-369 (2017)

${ }^{46}$ M. A. Freedman, Chem. Soc. Rev. 46, 7694-7705 (2017).

${ }^{47}$ A. K. Bertram, S. T. Martin, S. J. Hanna, M. L. Smith, A. Bodsworth, Q. Chen, M. Kuwata, A. Liu, Y. You, and S. R. Zorn, Atmos. Chem. Phys. 11(21), 1099511006 (2011).

${ }^{48}$ Q. Chen, C. L. Heald, J. L. Jimenez, M. R. Canagaratna, Q. Zhang, L. Y. He, X. F. Huang, P. Campuzano-Jost, B. B. Palm, L. Poulain, M. Kuwata, S. T. Martin, J. P. D. Abbatt, A. K. Y. Lee, and J. Liggio, Geophys. Res. Lett. 42(10), 4182-4189, https://doi.org/10.1002/2015gl063693 (2015).

${ }^{49} \mathrm{~B}$. Ervens, B. J. Turpin, and R. J. Weber, Atmos. Chem. Phys. 11(21), 1106911102 (2011).

${ }^{50}$ J. F. Pankow, M. C. Marks, K. C. Barsanti, A. Mahmud, W. E. Asher, J. Y. Li, Q. Ying, S. H. Jathar, and M. J. Kleeman, Atmos. Environ. 122, 400-408 (2015).

${ }^{51}$ Y. Rao, N. J. Turro, and K. B. Eisenthal, J. Phys. Chem. C 113(32), 1438414389 (2009)

${ }^{52}$ S. Paul and A. Chandra, J. Chem. Phys. 123(18), 184706 (2005).

${ }^{53}$ D. Zhang, J. H. Gutow, K. B. Eisenthal, and T. F. Heinz, J. Chem. Phys. 98(6), 5099-5101 (1993).

${ }^{54}$ S. Enami, M. R. Hoffmann, and A. J. Colussi, J. Phys. Chem. Lett. 1(15), 23742379 (2010).

${ }^{55}$ S. Mukherjee, A. Datta, A. Giglia, N. Mahne, and S. Nannarone, Langmuir 25(6), 3519-3528 (2009).

${ }^{56}$ M. T. C. Martins-Costa, J. M. Anglada, J. S. Francisco, and M. F. Ruiz-Lopez, J. Am. Chem. Soc. 134(28), 11821-11827 (2012).

${ }^{57}$ L. Vereecken and J. S. Francisco, Chem. Soc. Rev. 41(19), 6259-6293 (2012). ${ }^{58}$ C. Q. Zhu, M. Kumar, J. Zhong, L. Li, J. S. Francisco, and X. C. Zeng, J. Am. Chem. Soc. 138(35), 11164-11169 (2016).

${ }^{59}$ S. Enami and A. J. Colussi, J. Phys. Chem. Lett. 8, 1615-1623 (2017).

${ }^{60}$ L. v. B. Pártay, P. Jedlovszky, and G. Horvai, J. Phys. Chem. C 113(42), 1817318183 (2009).

${ }^{61}$ S. Paul and A. Chandra, J. Phys. Chem. B 109(43), 20558-20564 (2005)

${ }^{62}$ Y. Marcus, J. Chem. Soc., Perkin Trans. 2 1994(8), 1751-1758.

${ }^{63} \mathrm{~K}$. B. Eisenthal, Chem. Rev. 106(4), 1462-1477 (2006).

${ }^{64}$ M. J. Makowski, A. C. Stern, J. C. Hemminger, and D. J. Tobias, J. Phys. Chem. C 120(31), 17555-17563 (2016).

${ }^{65}$ K. A. Perrine, M. H. Van Spyk, A. M. Margarella, B. Winter, M. Faubel, H. Bluhm, and J. C. Hemminger, J. Phys. Chem. C 118(50), 29378-29388 (2014). ${ }^{66}$ T. G. Theofanous, V. V. Mitkin, C. L. Ng, C. H. Chang, X. Deng, and S. Sushchikh, Phys. Fluids 24(2), 022104 (2012).

${ }^{67} \mathrm{~J}$. Lasheras, E. Villermaux, and E. Hopfinger, J. Fluid Mech. 357, 351-379 (1998).

${ }^{68} \mathrm{~K}$. Kahen, K. Jorabchi, C. Gray, and A. Montaser, Anal. Chem. 76, 7194-7201 (2004).

${ }^{69}$ L. W. Zilch, J. T. Maze, J. W. Smith, G. E. Ewing, and M. F. Jarrold, J. Phys. Chem. A 112(51), 13352-13363 (2008).

${ }^{70} \mathrm{~S}$. Enami and A. J. Colussi, J. Chem. Phys. 138(18), 184706 (2013).

${ }^{71}$ L. W. Zilch, J. T. Maze, J. W. Smith, and M. F. Jarrold, Int. J. Mass Spectrom. 283(1-3), 191-199 (2009).

${ }^{72}$ A. Hirabayashi, M. Sakairi, and H. Koizumi, Anal. Chem. 67(17), 2878-2882 (1995). 
${ }^{73}$ J. Pól, T. J. Kauppila, M. Haapala, V. Saarela, S. Franssila, R. A. Ketola, T. Kotiaho, and R. Kostiainen, Anal. Chem. 79(9), 3519-3523 (2007).

${ }^{74}$ I. Manisali, D. D. Y. Chen, and B. B. Schneider, Trends Anal. Chem. 25, 243-256 (2006).

${ }^{75}$ M. Yamashita and J. B. Fenn, J. Phys. Chem. 88(20), 4451-4459 (1984).

${ }^{76} \mathrm{~S}$. Enami, T. Fujii, Y. Sakamoto, T. Hama, and Y. Kajii, J. Phys. Chem. A 120(46), 9224-9234 (2016).

${ }^{77}$ S. Enami, M. R. Hoffmann, and A. J. Colussi, J. Phys. Chem. Lett. 1(10), 15991604 (2010).

${ }^{78}$ S. Richters, H. Herrmann, and T. Berndt, Environ. Sci. Technol. 50(5), 2354-2362 (2016).

${ }^{79}$ J. Laskin, A. Laskin, and S. A. Nizkorodov, Anal. Chem. 90, 166-189 (2017).

${ }^{80}$ A. J. Ingram, C. L. Boeser, and R. N. Zare, Chem. Sci. 7(1), 39-55 (2016).

${ }^{81}$ S. Enami, M. R. Hoffmann, and A. J. Colussi, J. Phys. Chem. Lett. 8(16), 38883894 (2017).

${ }^{82}$ S. Enami and A. J. Colussi, J. Phys. Chem. A 121, 5175-5182 (2017)

${ }^{83}$ S. Enami and A. J. Colussi, Phys. Chem. Chem. Phys. 19, 17044-17051 (2017).

${ }^{84}$ R. Winterhalter, F. Herrmann, B. Kanawati, T. L. Nguyen, J. Peeters, L. Vereecken, and G. K. Moortgat, Phys. Chem. Chem. Phys. 11(21), 4152-4172 (2009).

${ }^{85}$ Y. Sakamoto, S. Inomata, and J. Hirokawa, J. Phys. Chem. A 117(48), 1291212921 (2013).

${ }^{86}$ J. W. Larson and T. B. McMahon, J. Am. Chem. Soc. 107(4), 766-773 (1985).

${ }^{87}$ N. Heine, F. A. Houle, and K. R. Wilson, Environ. Sci. Technol. 51(23), 1374013748 (2017).

${ }^{88}$ J. Cheng, M. R. Hoffmann, and A. J. Colussi, J. Phys. Chem. B 112(24), 71577161 (2008).

${ }^{89} \mathrm{~J}$. Cheng, C. Vecitis, M. R. Hoffmann, and A. J. Colussi, J. Phys. Chem. B 110, 25598-25602 (2006).

${ }^{90}$ T. Takamuku, A. Yamaguchi, M. Tabata, N. Nishi, K. Yoshida, H. Wakita, and T. Yamaguchi, J. Mol. Liq. 83(1-3), 163-177 (1999).

${ }^{91}$ T. Oguchi, A. Wakisaka, S. Tawaki, H. Tonami, H. Uyama, and S. Kobayashi, J. Phys. Chem. B 106(6), 1421-1429 (2002).

${ }^{92}$ D. N. Shin, J. W. Wijnen, J. Engberts, and A. Wakisaka, J. Phys. Chem. B 106(23), 6014-6020 (2002).
${ }^{93}$ S. Shimizu and N. Matubayasi, Phys. Chem. Chem. Phys. 20(20), 1377713784 (2018).

${ }^{94}$ R. Pinal, P. S. C. Rao, L. S. Lee, P. V. Cline, and S. H. Yalkowsky, Environ. Sci. Technol. 24(5), 639-647 (1990).

${ }^{95}$ C. Yang, W. Li, and C. Wu, J. Phys. Chem. B 108(31), 11866-11870 (2004).

${ }^{96}$ J. P. D. Abbatt, A. K. Y. Lee, and J. A. Thornton, Chem. Soc. Rev. 41(19), 6555-6581 (2012).

${ }^{97}$ A. D. Estillore, J. V. Trueblood, and V. H. Grassian, Chem. Sci. 7(11), 66046616 (2016).

${ }^{98}$ J. S. Hub, C. Caleman, and D. van der Spoel, Phys. Chem. Chem. Phys. 14(27), 9537-9545 (2012).

${ }^{99}$ C. E. Kolb, R. A. Cox, J. P. D. Abbatt, M. Ammann, E. J. Davis, D. J. Donaldson, B. C. Garrett, C. George, P. T. Griffiths, D. R. Hanson, M. Kulmala, G. McFiggans, U. Poschl, I. Riipinen, M. J. Rossi, Y. Rudich, P. E. Wagner, P. M. Winkler, D. R. Worsnop, and C. D. O'Dowd, Atmos. Chem. Phys. 10(21), 10561-10605 (2010).

${ }^{100}$ T. P. Liyana-Arachchi, C. Stevens, A. K. Hansel, F. S. Ehrenhauser, K. T. Valsaraj, and F. R. Hung, Phys. Chem. Chem. Phys. 15(10), 3583-3592 (2013).

${ }^{101}$ K. Matsuoka, Y. Sakamoto, T. Hama, Y. Kajii and S. Enami, J. Phys. Chem. A 121, 810-818 (2017)

${ }^{102}$ V. F. McNeill, N. Sareen, and A. N. Schwier, in Atmospheric and Aerosol Chemistry, edited by V. F. McNeill and P. A. Ariya (Springer, 2014), Vol. 339, pp. 201-259.

${ }^{103}$ B. Bonn, G. Schuster, and G. K. Moortgat, J. Phys. Chem. A 106(12), 28692881 (2002).

${ }^{104}$ Y. B. Lim and B. J. Turpin, Atmos. Chem. Phys. 15(22), 12867-12877 (2015).

${ }^{105}$ M. Riva, S. H. Budisulistiorini, Z. F. Zhang, A. Gold, J. A. Thornton, B. J. Turpin, and J. D. Surratt, Atmos. Environ. 152, 314-322 (2017).

${ }^{106} \mathrm{~J}$. Valverde-Canossa, W. Wieprecht, K. Acker, and G. K. Moortgat, Atmos. Environ. 39(23-24), 4279-4290 (2005).

${ }^{107}$ M. Y. Wang, L. Yao, J. Zheng, X. K. Wang, J. M. Chen, X. Yang, D. R. Worsnop, N. M. Donahue, and L. Wang, Environ. Sci. Technol. 50(11), 5702-5710 (2016).

${ }^{108}$ Q. Zhao, W. Wang, F. Liu, J. Lu, and W. Wang, Atmos. Environ. 166, 1-8 (2017). 